\title{
Production and Partial Purification of the Grapevine Fanleaf Virus Coat Protein 42 Polyclonal Antibody Against Inclusion Body Expressed in Escherichia coli
}

\author{
Naeimeh Shibaei ${ }^{1}$, Jafar Majidi ${ }^{2,3^{*}}$, Nemat Sokhandan Bashir ${ }^{4,}$ Aliasghar Karkhaneh ${ }^{5}$, Khadijeh Razavi ${ }^{1^{*}}$ \\ ${ }^{1}$ Department of Agricultural Biotechnology, National Institute of Genetic Engineering and Biotechnology (NIGEB), Tehran, Iran \\ ${ }^{2}$ Immunology Research Center, Tabriz University of Medical Sciences, Tabriz, Iran \\ ${ }^{3}$ Department of Immunology, Faculty of Medicine, Tabriz University of Medical Sciences, Tabriz, Iran \\ ${ }^{4}$ Plant Protection Department, The University of Tabriz, 29 Bahman Blvd., Tabriz, Iran \\ ${ }_{5}^{5}$ Department of Industrial and Environmental Biotechnology, National Institute of Genetic Engineering and Biotechnology (NIGEB), \\ Tehran, Iran
}

"Corresponding authors: Jafar Majidi and Khadijeh Razavi, National Institute of Genetic Engineering and Biotechnology, Shahrak-e Pajoohesh, km 15, Tehran - Karaj Highway, P.O. Box:14965/161, Tehran, Iran. Tel:+98 21 44787307, majidij@tbzmed.ac.ir; razavi@nigeb.ac.ir

Received: 16 Mar. 2016; $\quad$ Revised: 5 May. 2018; $\quad$ Accepted: 12 Jun. 2018; $\quad$ Published online: 12 Dec. 2018

\begin{abstract}
Background: Expression of virus coat protein (CP) in Escherichia coli often leads to production of partially folded aggregated proteins which are called inclusion bodies. Grapevine fanleaf virus (GFLV) is one of the most serious and widespread grapevine virus diseases around the world and in Iran.

Objective: The main objective of this study was to find a simple and brief method for producing polyclonal antibodies (PAbs) to be used for immunodiagnosis of GFLV.

Material and Methods: An antigenic determinant in GFLV CP gene was inserted into pET-28a bacterial expression vector and the construct (pET-28a CP42) was cloned into E. coli strain BL21 (DE3).

The recombinant coat protein of GFLV (CP42) was expressed and characterized by SDS-PAGE and western blot analysis using commercial anti-GFLV antibody. Expression of the CP was detected in the form of inclusion bodies in insoluble cytoplasmic fraction. Then, the inclusion bodies were isolated from the bacterial cells and injected into rabbits for PAbs production. The reaction of the antiserum was checked by ELISA assay. In order to analyze efficiency of the produced PAbs, first the infected and uninfected grapevine samples were confirmed based on morphological symptoms then the indirect plate- trapped antigen Enzyme-linked Immunosorbent Assay (IPTA-ELISA) was applied using the commercial anti GFLV antibody. In the next ELISA assay, efficiency of the raised polyclonal antibody was compared with commercial one.

Results: The expression of recombinant CP42 induced by IPTG was confirmed by the band of $42 \mathrm{kDa}$ in SDS-PAGE and western blot. The antiserum of purified inclusion body immunized rabbit was reacted with CP42 and GFLV infected Grapevine samples. The results revealed an acceptable efficacy for prepared antibodies compared to that of commercial antibody.

Conclusions: It was evident that the recombinant coat protein in the form of inclusion bodies can be prepared and used as the antigen for immunizing animals in order to produce PAbs.

Keywords: Polyclonal antibodies, inclusion body, recombinant coat protein, GFLV, Enzyme-Link Immunosorbent Assay (ELISA).
\end{abstract}

\section{Background}

Polyclonal antibodies are produced as the result of proliferation and differentiation of the lymphocytes into plasma cells in response to the highly complex antigens with various epitopes. A monoclonal antibody is made by one lineage of lymphocyte B cells against each epitope, whereas polyclonal antibodies refer to antibodies which are made by the collective lineages of the B cells each responding to one epitope. In a simple word, polyclonal antibodies are a collection of different monoclonal antibodies. Conformational changes have a lower effect on the activity of the polyclonal antibodies as they are able to recognize multiple epitopes in the target antigen (1). Due to the ability of the polyclonal antibodies for

Copyright (C 2018 The Author(s); Published by National Institute of Genetic Engineering and Biotechnology. This is an open access article, distributed under the terms of the Creative Commons Attribution-NonCommercial 4.0 International License (http://creativecommons.org/licenses/ by-nc/4.0/) which permits others to copy and redistribute material just in noncommercial usages, provided the original work is properly cited. 
binding to more than one antigen and forming a large participating lattice which depends on the concentration of the antibody and antigen, these antibodies are suitable for the immunoprecipitation of the complex antigens and most of immunochemical techniques such as Western blotting, immunocapture-polymerase chain reaction (ICPCR) (2), immunosorbent electron microscopy (ISEM) (3), and indirect plate-trapped ELISA. It is notable that polyclonal antibodies generation requires less technical skills, time, cost, and its production is much more rapid than that of monoclonal antibodies (1).

The advent of molecular techniques was made it possible to amplify, clone, and express viral structural protein genes such as coat proteins (CPs). Then, polyclonal and monoclonal antibodies are produced against the purified recombinant $\mathrm{CP}$ as the antigen (4, 5).

Grapevine fanleaf virus (GFLV) is one of the most destructive and widespread viral diseases of the grapevine. As a member of the genus Nepoviruses and the family Secoviridae (6), GFLV is spread by the ectoparasitic nematode Xiphinemaindex $(7,8)$ and a vegetative propagation of the infected stocks (9). The GFLV virion is a pseudo-T $=3$ icosahedral particle formed from 60 subunits (10); each subunit containing 504 amino acids (56,019 Da) (11).

Grapevines infected by the GFLV have a lower fruit yield and quality, misshapen leaves, shortened internodes, yellowed and mottled leaves (9). The crop loss ranges from moderate $(5-10 \%)$ to a very high (up to $90 \%$ or more) depending on the virus strain virulence and varietal susceptibility. The vegetative propagation of the shoot stock is the most important proliferation method of the grapevine breeding. This virus is widely spread over a long distance by the infected cutting stocks (12). Detection of the GFLV, as is the case with other viruses, is a prerequisite in the elimination of the pathogen (13). For the virus control, several efforts have been attempted such as clean-stock certification program in the vineyards and regular screening of the vines by Enzyme-Link Immunosorbent Assay (ELISA).

Conventionally, virus particles are used as the viral antigen for production of polyclonal and monoclonal antibodies. Since virus purification is a very sensitive process and needs a very expensive equipment (14), this method has been replaced by recombinant DNA technology for production of the structural proteins such as viral CPs $(15,16)$. One advantage of this system is the production of the protein (antigen) in large quantities (17). Recombinant proteins are expressed as native protein or inclusion bodies in the bacterial cells. The purification of the recombinant proteins from inclusion bodies is a labor-intensive and timeconsuming process. An inclusion body is both partially folded and aggregated protein that has maintained all of linear and some of the conformational epitopes. Viral CP expression in the E. coli usually leads to the formation of aggregated proteins; inclusion bodies, which are and stainable. Such an aggregated state of the proteins is commonly occurring during overexpression of the heterologous genes in the E. coli; particularly genes of the viral or mammalian sources (18).

Polyclonal antibodies were recently prepared against GFLV CP expressed in the E. coli (16), however in the present study only $42 \mathrm{kDa}$ segment of the $\mathrm{CP}$ gene that was predicted to contain epitopes; a shortened segment more than $56 \mathrm{kDa}$ of the whole protein, was synthesized and expressed in the form of inclusion body. Then, the inclusion body was used as the antigen.

\section{Objectives}

Yang et al. (2011) have demonstrated a rapid method for polyclonal antibody production based on utilization of inclusion body as the antigen(19). The aim of this study was to develop rabbit polyclonal antibodies against recombinant GFLV CP using inclusion bodies as the antigen in order to optimize a simple and brief method for producing polyclonal antibodies for immunediagnosis of GFLV.

\section{Materials and Methods}

\subsection{Ethical Approval}

All authors hereby declare that "Principles of laboratory animal care" (NIH publication No. 85-23, revised 1985) were followed, as well as specific national laws wherever it was demanded. All experiments have been examined and approved by the appropriate ethics committee.

\subsection{Chimeric Construct Synthesis and Expression}

A synthetic 1133 bp DNA coding for potential epitopes of GFLV CP (GenBank, KU640965) was chemically synthesized by the ShineGene Molecular Biotech (Shanghai, People's Republic of China). The synthetic gene was sub-cloned into pET-28a expression vector (Novagen, USA) between $N c o$ I and XhoI restriction sites (Fig. 1) according to Shibaei et al. (2017) (20).

\subsection{Solubility Test and Purification of Recombinant Protein}

The pellet of bacterial culture was re-suspended in the 


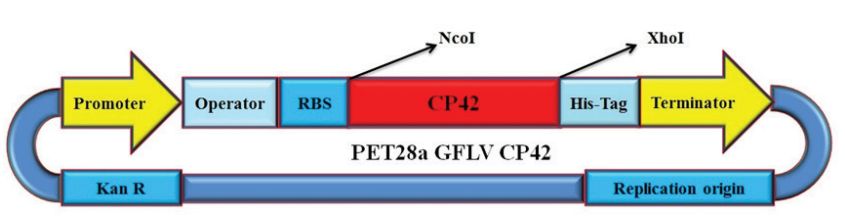

Figure 1. A diagram showing antigenic determinant in Grapevine fanleaf virus coat protein gene cloned into the expression vector.

lysis buffer (100 mM Tris-Cl pH 8.0, $100 \mathrm{mM} \mathrm{NaCl}$, $0.5 \%$ Triton X100, and $100 \mu \mathrm{g} . \mathrm{mL}^{-1}$ lysozyme) before subjecting to sonication. Then, inclusion bodies were collected by centrifugation at $14000 \times \mathrm{g}$ for $20 \mathrm{~min}$ at $4{ }^{\circ} \mathrm{C}$. Initially, the inclusion bodies were washed with washing buffer $(0.5 \%$ Triton X100, $100 \mathrm{mM} \mathrm{NaCl}, 100$ $\mathrm{mM}$ Tris-Cl, $\mathrm{pH} 8.0$ ), then with phosphate buffered saline (PBS), and stored at $-20{ }^{\circ} \mathrm{C}$ until being used. Protein concentration was measured by the method of Yang et al. (19).

\subsection{Western Blot Analysis}

The purified protein was transferred from SDS-PAGE gel to polyvinylidene fluoride (PVDF) membrane (Biocom Semi-Dry Blotters, UK) and Western blot analysis was carried out as described previously (20).

\subsection{Immunization Method}

A 6-month-old New Zealand white rabbit was immunized by aliquots of the extracted inclusion body as described previously by Majidi et al (2007) (21).

\subsection{Titration of the Antiserum}

The antiserum was titrated against CP42 in a platetrapped antigen (PTA)-ELISA by the method elucidated by Sokhandan et al. (2015) with modifications (16).

\subsection{Purification of the Rabbit Anti-CP42}

We used an ion-exchange chromatography (IEC) basedmethod to purify rabbit anti-CP42 protein (Majidi et al, 2007) (21). Finally, the eluted proteins were collected in about $2 \mathrm{~mL}$ fractions and were analyzed by the SDSPAGE by loading the adjusted equal amounts of protein into each well.

\subsection{Efficiency of the Anti-CP42 IgG in IPTA-ELISA}

In order to determine the efficiency of anti-CP42 antibody for detection of GFLV in the vineyards, the virus-infected symptomatic vine samples were collected from vineyards in Maragheh, Bonaband, Urmia, Iran. Then, the efficiency of the analysis was estimated as described before (20).

\section{Results}

4.1. Recombinant CP42 Expression, Purification, and Characterization

The synthetic gene was expressed in the E. coli BL21 (DE3).The optimum condition for the CP42 expression was achieved after $7 \mathrm{~h}$ induction by IPTG $(1 \mathrm{mM})$, at $37^{\circ} \mathrm{C}$ and OD600 of 0.9 . The solubility test of the CP42 indicated that the majority of the expressed protein was in the insoluble fraction. SDS-PAGE analysis revealed the presence of the expressed CP42 as a major band (42 $\mathrm{kDa}$ ) in the all sedimented fractions (Fig. 2).

Furthermore, when the purified inclusion body samples from the bacteria expressing CP gene was subjected to the Western blotting they reacted with the commercial anti-GFLV antibody and developed strong spots, whereas no signals were produced with the uninduced control sample (Fig. 3).

\subsection{Titration of the Rabbit Anti-CP42 Antibody}

In an indirect ELISA, the antiserum raised in the rabbit and diluted to 1:2000 was the most reactive antiserum, while antiserum diluted to 1:64000 still showed the minimal reactivity. However, all dilutions were effective in the detection of the CP42 using indirect ELISA. The anti- CP42 serum had a titer of 64000 as determined by the PTA-ELISA (Fig. 4). This recombinant antiserum reacted with the expressed GFLV CP and detected GFLV in the infected plant tissue.

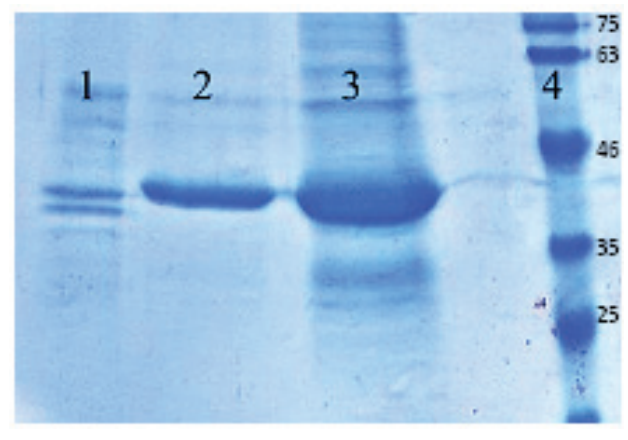

Figure 2. Purification of the CP42 from pET-28a. Lane 1, supernatant or washed elution. Lane 2, purified inclusion body. Lane 3, the expressed bacterial protein. Lane 4, protein molecular weight marker.

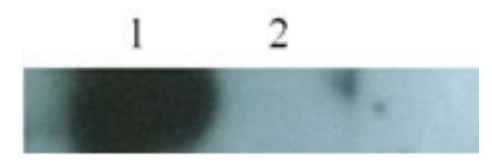

Figure 3: Western blot analysis of the CP 42 using anti-GFLV antibody. Lane 1, extracted inclusion body from the induced bacterial extract. Lane 2, un-induced bacterial extract as negative control. 


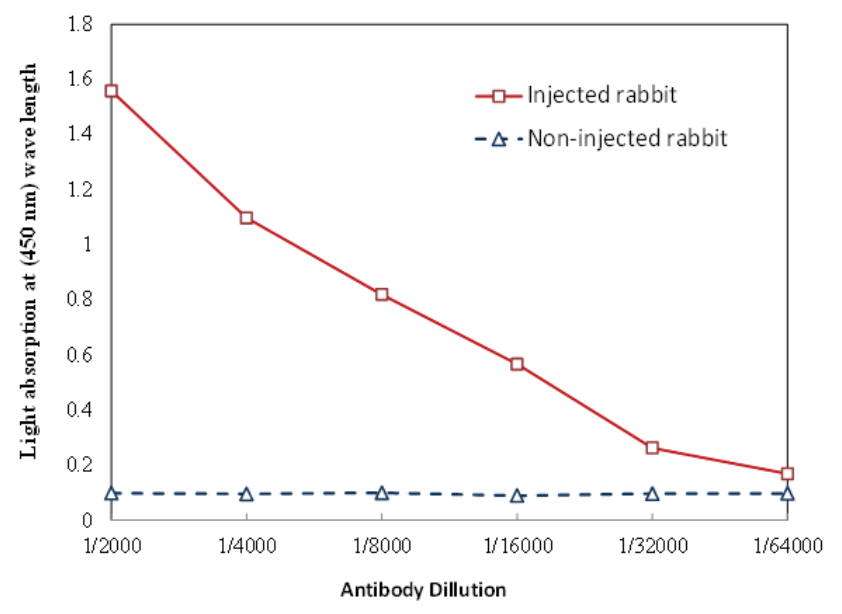

Figure 4. . The titration curve of the prepared antiserum against recombinant $\mathrm{CP} 42$ coat protein (CP42) by the use of indirect ELISA. The graph is based on absorbance values of the wells treated with the different dilutions of the antiserum. ELISA readings were recorded after 15 min of incubation with the TMB substrate at a wavelength of $450 \mathrm{~nm}$. The ELISA readings greater than twice absorbance value of the control were considered as positive. The recorded O.D. data are mean of the optical absorbance.

\subsection{Purification of the Rabbit Anti-CP42 Antibody}

Purification of the polyclonal antibodies from an immunized rabbit was performed by DEAE ionexchange chromatography and resulted in a highly purified fraction (Fig. 5). The protein content of this fraction after elution from IEC was $5 \mathrm{mg}$, which was about one-eighth of the primary protein content (about $40 \mathrm{mg}$ ) and its purity was determined by SDS-PAGE (Fig. 6). A distinct band with a molecular weight of about $50 \mathrm{kDa}$ indicates the heavy chains of the rabbit $\mathrm{IgG}$, and the protein bands of being $20-30 \mathrm{kDa}$ in size are indicators of the light chains of rabbit IgG, respectively. The purity of the rabbit anti-CP42 was more than $95 \%$ in some fractions as estimated by the spectrophotometer. The eluted proteins were collected in $\sim 2 \mathrm{~mL}$ fractions and were analyzed by the SDSPAGE using the adjusted equal amounts of protein loading into the wells. Repeated measurement of the OD helped out to estimate the exact elution time. One of the best fractions had an OD $=6$. The SDSPAGE analysis showed that IgG purification by ionexchange chromatography resulted in a very purified and acceptable product.

\subsection{Efficiency Analysis of the Purified Rabbit Anti- CP42 Antibody}

An IPTA- ELISA test was done in order to determine

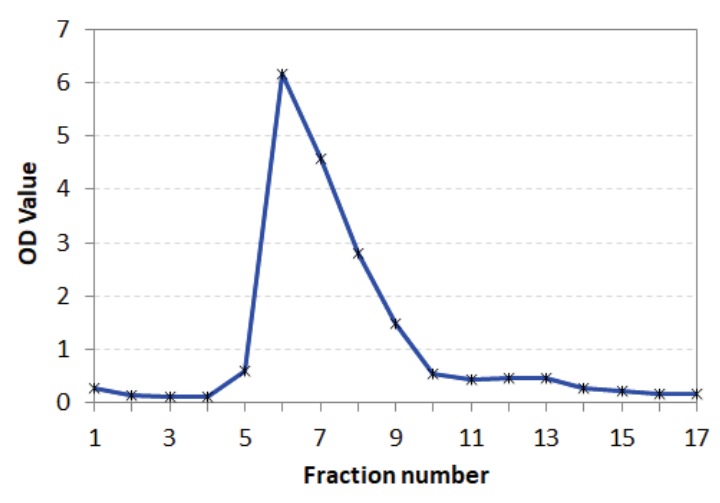

Figure 5. Chromatography pattern of purified rabbit anti-GFLV antibody by ion-exchange column using Trisphosphate buffer (pH 8.1) containing $100 \mathrm{mM}$ of $\mathrm{NaCl}$. The recombinant antibody elutes as a single peak indicating the presence of one protein in the eluted fraction.

the efficiency of the anti-CP42 in detecting GFLV and comparison of which to that of anti-GFLV in discriminating the infected and non-infected grapevine samples. Grapevine samples were collected based on the Morphological symptoms such as yellow mosaic pattern on leaf, open petiole leaf, open petiole leaf, the vein banding, leaf deformation, and mottling.

For ELISA confirmation assay, 4 uninfected and 10 infected plants with typical symptoms were chosen. ELISA was done using standard polyclonal anti-GFLV antibody. The OD value of the infected samples was at least twice than those of non- infected samples. Other ELISA assays confirmed the efficiency of the anti-CP42 antibody. Antigen (i.e., the crude extract of the grapevine) coated directly onto the ELISA plate upon incubation with CP42 antiserum showed a higher absorbance value with the infected samples than that of healthy controls. Accordingly, antigen detection efficiency of the anti-CP42 was exactly the same as that of commercial anti-GFLV antibody (Fig.7).

In the present study, the possible cross-reactivity of the prepared anti-CP42 antibody with the other non-

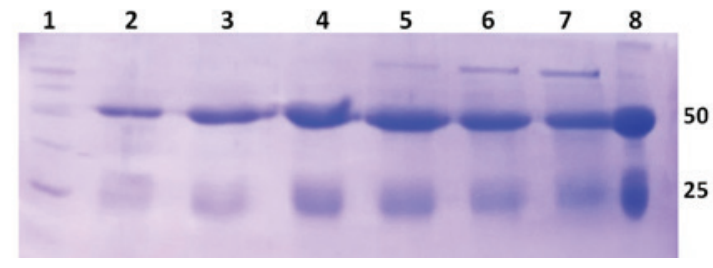

Figure 6. SDS- PAGE of purified rabbit anti-CP42 antibody in reduced condition. Two bands approximate of 25 and $50 \mathrm{kDa}$, corresponding to the heavy and light chains were detected. Lane 1,protein marker. Lane 2-9, fraction number. 


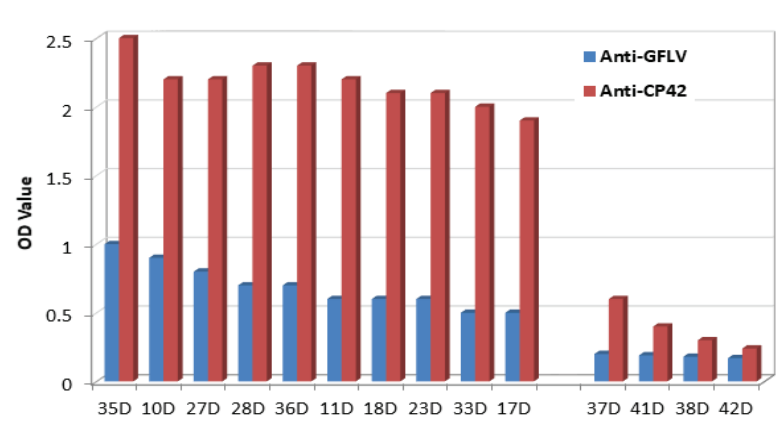

Figure 7. Comparing efficiency of anti-CP42 and anti-GFLV antibodies in the virus detection. Ten infected samples present in the left hand of chart and 4 non-infected samples presented in the right hand. The curve is based on absorbance values at $450 \mathrm{~nm}$.

specific plant proteins such as that of poplar and pine plants were examined in the ELISA assay. Results showed the mean values of 0.73 and 0.61 of the optical density for the poplar and pine plants' protein, respectively, which was significantly lower than that of the infected grapevine samples.

\section{Discussion}

Many studies have been conducted to introduce a simple and reliable method for the mass production of the antibodies. These achievements have allowed a widespread usage of the antibodies as a diagnostic tool for on-time detection and subsequent prevention of disease expansion. In this study, GFLV CP expressed in the $E$. coli was purified and applied as an immunogen for the production of the polyclonal anti-GFLVCP42 antibody. It was found that the expressed protein was mainly in the form of inclusion bodies. This was predictable as it has been reported that GFLV CP possesses hydrophobic properties (11) and the hydrophobic interactions among the partially folded protein molecules are responsible for aggregation of recombinant protein into inclusion bodies (22).

In the present study, sonication and high-speed centrifugation were used for cell disruption as well as inclusion body separation. This is in accordance with a previous report that inclusion bodies have higher densities $\left(\sim 1.3-1 \mathrm{mg} \cdot \mathrm{mL}^{-1}\right)$ than many cellular components, and as a result, the inclusions can be easily separated by the high-speed centrifugation after cell disruption (23). The purity of the inclusion body in this paper was estimated by electrophoretic methods as a simplest and the least expensive approach (24) to be approximately $90 \%$ using SDS-PAGE electrophoresis. Although in the present study inclusion body was produced in the bacterial host system, however, the bacterial impurity and related antibody did not reduce the specificity of the polyclonal antibodies which were used for detection of the GFLV infection in the plant sample.

In addition, the antiserum raised against the GFLV $\mathrm{CP}$ in the form of inclusion bodies efficiently detected the related viral antigen in the infected plant sample in IPTA-ELISA. Antibodies against recombinant viral proteins from plants other than grapevine such as Potato mop-top virus (PMTV) and Watermelon mosaic virus (WMV) have already been prepared and used for diagnosis of the respective diseases . In both cases, the produced antibodies were more specific; resulted in a reduced occurrence of unexpected heterologous reactions (25). This feature was also shown by Fajardo et al, based on preparation of antibodies against Grapevine leafroll-associated virus 3 (GLRaV-3) (14). Yang et al. used the intact inclusion bodies as the antigens for antibody production. They directly injected the intact inclusion bodies into rabbits and hens (19). Likewise, in the present study, GFLV CP in the form of inclusion bodies was used as the antigen in order to produce polyclonal antibodies. The result obtained through the application of ELISA together with the Western blotting assay confirmed the specificity of the polyclonal antibodies. Moreover, results from the present study have demonstrated that the antiserum produced against the recombinant viral $\mathrm{CP}$ in the form of inclusion bodies was able to detect the related viral antigen in the infected plant sample in IPTA-ELISA.

Antibodies' breadth of reactivity and affinity are related to three main factors including the concentration of the covering antigen, epitope masking, and the number of presented antigens (26). Antibodies with both the high and low affinity can bind to high amount of antigen that is used to immunize the rabbit. Therefore, a few antibodies with low affinity will provide enough efficiency for serological tests. Several reports have suggested that B-cell populations are limited by antigen availability and on the other hand rate of affinity maturation is dependent on the competition between B cells for the antigen as well as the supporting helper $\mathrm{T}$ cells (27). The immune system intelligently chooses the high adaptation to a few epitopes or lower adaptation to many epitopes. So, the mean affinity strength of the antibody will be decreased due to an increase in the number of the epitopes (28). Here, the antigen dosage of each injection was not reduced. Therefore, the antigen availability with one or a few epitopes did not limit the immune system. Probably, multiple B-cells were involved in the immune system and some of them were capable of identifying native virions. 
The second factor is the role of conserved epitopes of inclusion bodies and native protein that may justify the ability of antisera produced against inclusion body for detecting the related viral antigens. There will be a higher possibility of obtaining specific antibodies against native protein if dominant epitopes are not hidden inside the inclusion bodies (26). Since the formation of the inclusion bodies is a result of an intracellular accumulation of the partially- folded expressed proteins, then the epitopes on inclusion bodies are not predic (23). By the reason of partially folding properties of the inclusion bodies, all the continuous and some of the conformational epitopes have been conserved. In other words, native hosts respond to antigen and produce antibody against various epitopes by two mechanisms: a consistent pattern of immunodominance, by which, the majority of the induced B cells target the same epitope (29) or adaptation to the different epitopes (27). The probability of cross-reactive antibody production arises from conserved epitopes of the inclusion bodies and native protein is further in the second mechanism (adaptation to different epitopes), although the kind of response is related to antigen type and genetic diversity of the hosts' naive B-cell population (26). As a result, in this experiment, the ability of the prepared antibodies to identify the whole virus may suggest that the antigen does not have immuno-dominant epitopes and the host (rabbit) responds by the adaptation to the different epitopes.

The last important factor that may justify ability of anti-recombinant $\mathrm{CP}$ antibody for detection of the whole virus in the infected sample's protein is the effect of virus extraction buffer. The icosahedral GFLV capsid is formed by 60 copies of the $\mathrm{CP}$ arranged according to a pseudo $\mathrm{T}=3$ symmetry (10). Then, the only accessible region of the whole capsid could be identified by the antibody as epitope and major region of each subunit of capsid become hidden. A combination of hydrophobic attractions, electrostatic repulsions, and specific contacts between certain pairs of the amino acids (known as 'Caspar pairs') cause capsid proteins interaction (30). Changes in the ionic strength, $\mathrm{pH}$, and temperature can affect both protein-protein interactions in the virion assembly and disassembly (31). Hence, virus extraction buffer of an infected sample will have an effect on the capsid disassembling and resulting in the dissociation of the capsid proteins and exposure of the hidden epitopes. There are different suggested protocols for virus extraction buffer to be applied in ELISA assay $(10,32)$. One of the precise experiments about GFLV was performed by Schellenberger et al. They extracted the whole virus from infected source and then used it for the crystallization of the virus (10).
Their used buffers were composed of $0.1 \mathrm{M}$ sodium phosphate buffer $\mathrm{pH} 7.2,0.1 \mathrm{M}$ ascorbic acid, and 0.01 M EDTA, in the presence of $8.5 \%$ (w/v) butanol (33) which is different from our buffer in the ionic strength and salt composition. We could not find any document about the effect of extraction buffer on the release of intact virus particles or disassembled coat protein, but it seems an apparent difference in the virus extraction buffer as it has caused virion disassembly during the whole virus extraction from infected plants and may have caused exposure of the hidden epitopes of the virus coat protein (31). Then, the number of epitopes were increased and resulted in an increased probability of the whole virus detection.

While PTA-ELISA method was performed for evaluating the efficacy of the polyclonal antibodies, some of the infected and uninfected plants which were selected based on symptoms were used as whole virus sources and negative control, respectively. Subsequently, two different ELISA tests were performed separately with the commercial and newly- made antibody. Afterwards, antibodies efficiency was compared with that of commercial antibody. Results demonstrated that the performance of the antibody was similar to that of commercial antibody. However, the absorbance values from grapevine infected samples suggest that the virus titer was low in the grapevine samples under evaluation. As a result, PTA- ELISA was a completely efficient test for the examination of the newly- made polyclonal antibodies. Thereby, we suggest further works in future on the cross-reactivity of the anti-GFLV antibody against other grapevine viruses.

This study has demonstrated the reactivity of the anti-CP42 antibodies against the whole virus using IPTA-ELISA. The efficiency of the polyclonal antibody produced against inclusion bodies is comparable with that of commercial polyclonal antibody. Thereby, the recombinant inclusion body of the GFLV coat protein is a very useful antigen for the production of the polyclonal antibodies for research and diagnostic applications. This is the first report of using synthetic GFLV CP in the form of inclusion body from an Iranian isolate of this virus which designed in order to produce an antibody for diagnostic kits.

Moreover, the polyclonal antibody prepared against GFLV was demonstrated to be efficient in the detection of the either the purified CP or the virus in ELISA. Availability of such antibodies facilitates screening of apparently healthy mother vine grapevine material prior to them being propagated for planting in nurseries and are being implicated in the studies on the pathogenicity of the virus. 


\section{Acknowledgments}

We would like to thank National Institute of Genetic Engineering and Biotechnology (NIGEB), the Immunology Research Center (IRC), and Drug Applied Research Center for their kind assistance. The manuscript was written based on a dataset of a $\mathrm{PhD}$. thesis registered in National Institute of Genetic Engineering and Biotechnology.

\section{References}

1. Lipman NS, Jackson LR, Trudel LJ, Weis-Garcia F. Monoclonal versus polyclonal antibodies: distinguishing characteristics, applications, and information resources. ILARJ. 2005;46(3):258268. doi: 10.1093/ilar.46.3.258

2. Koolivand D, Sokhandan-Bashir N, Behjatnia SAA, Jafari Joozani RA. Detection of Grapevine fanleaf virus by immunocapture reverse transcription-polymerase chain reaction (IC-RT-PCR) with recombinant antibody. Arch Phytopathology Plant Protect. 2014;47(17):2070-2077. doi: 10.1080/03235408.2013.868697

3. Ritzenthaler C, Laporte C, Gaire F, Dunoyer P, Schmitt C, Duval S, et al. Grapevine Fanleaf Virus Replication Occurs on Endoplasmic Reticulum-Derived Membranes. J Virol. 2002;76(17). 8808-8819. doi: 10.1128/JVI.76.17.88088819.2002

4. Böldicke T. Polyclonal Antibodies for Detection of Witchesâ€ $€^{\mathrm{TM}}$ Broom Disease of Lime. IJBiotech. 2013;11(3):144. doi: 10.5812/ijb.12619.

5. Zhang J, Jin Z, Sun T, Jiang Y, Han Q, Song Y, et al. Prokaryotic Expression, Purification, and Polyclonal Antibody Production of a Truncated Recombinant Rabies Virus L Protein. IJBiotech. 2015;13(2):18-24. doi:10.15171/ijb.1022

6. King A, Adams M, Carstens E, Lefkowitz E. Virus taxonomy: classification and nomenclature of viruses: Ninth Report of the International Committee on Taxonomy of Viruses. In: The standard and definitive reference for virus taxonomy. San Diego: Elsevier Academic Press; 2012. 1327 p. doi: 10.1016/ b978-0-12-384684-6.00115-4

7. Andret-Link P, Schmitt-Keichinger C, Demangeat G, Komar V, Fuchs M. The specific transmission of Grapevine fanleaf virus by its nematode vector Xiphinema index is solely determined by the viral coat protein. Virology. 2004;320(1):12-22. doi: 10.1016/j.virol.2003.11.022

8. Raski D, Goheen A, Lider L, Meredith C. Strategies against grapevine fanleaf virus and its nematode vector. Plant Dis. 1983;67(3):335-338. doi:10.1094/pd-67-335

9. Andret-Link P, Laporte C, Valat L, Ritzenthaler C, Demangeat $\mathrm{G}$, Vigne E, et al. Grapevine fanleaf virus: still a major threat to the grapevine industry. J Plant Pathol. 2004;86(3):183-195. doi:10.1094/PHYTO-95-1151. (14).

10. Schellenberger P, Sauter C, Lorber B, Bron P, Trapani S, Bergdoll $\mathrm{M}$, et al. Structural insights into viral determinants of nematode mediated Grapevine fanleaf virus transmission. PLoS Pathog. 2011;7(5):e1002034. doi: 10.1371/journal.ppat.1002034

11. Serghini M, Fuchs M, Pinck M, Reinbolt J, Walter B, Pinck L. RNA2 of grapevine fanleaf virus: sequence analysis and coat protein cistron location. J Gen Virol. 1990;71(7):1433-41.doi: 10.1099/0022-1317-71-7-1433.

12. Pearson RC and GoheenAC. Compendium of Grape Diseases,
(Eds.), APS Press, St. Paul, Minnesota, USA., 1989;48-49. doi: $10.2307 / 3759482$

13. Sokhandan- Bashir N, Khabbazi AD, Torabi E. Isolation of the gene coding for movement protein from Grapevine fanleaf virus. I J Biotech. 2009;7(4):258-261.

14. Fajardo TV, Barros DR, Nickel O, Kuhn GB, Zerbini FM. Expression of Grapevine leafroll-associated virus 3 coat protein gene in Escherichia coli and production of polyclonal antibodies. Fitopatol. Bras. 2007;32(6):496-500. doi: 10.1590/ s0100-41582007000600007

15. Huss B, Muller S, Sommermeyer G, Walter B, Regenmortel M. Grapevine fanleaf virus monoclonal antibodies: their use to distinguish different isolates. $J$ Phytopathology. 1987;119(4):358-370. doi: 10.1111/j.1439-0434.1987. tb04406.x

16. Sokhandan-Bashir N, Koolivand D, Behjatnia SAA. Preparation of Polyclonal Antibodies to Grapevine fanleaf Virus Coat Protein Expressed in Escherichia coli. Biotechnology, 2015;14(4):173180. doi: 10.3923/biotech.2015.173.180

17. Andersen DC, Krummen L. Recombinant protein expression for therapeutic applications. Curr Opin Biotechnol. 2002;13(2):117123. doi: 10.1016/s0958-1669(02)00300-2

18. 18. Ventura S, Villaverde A. Protein quality in bacterial inclusion bodies. Trends Biotechnol. 2006;24(4):179-185.doi: 10.1016/j.tibtech.2006.02.007

19. Yang H, Zhang T, Xu K, Lei J, Wang L, Li Z, et al. A novel and convenient method to immunize animals : Inclusion bodies from recombinant bacteria as antigen to directly immunize animals. Afr J Biotechnol. 2011;10(41):8146-8150.doi: 10.5897/AJB10.2681

20. Shibaei N, Majidi J, Razavi K, Karkhane AA, SokhandanBashir N, Aghebati-Maleki L. Production and Characterization of Monoclonal Antibody against Recombinant Virus Coat Protein CP42. Iran J Allergy Asthma Immunol. 2017; 16(1):6071.

21. Majidi J, Abdolalizadeh J, Amirkhiz MB, Majidi S. Production and purification of polyclonal antibody against bovine immunoglobulins in rabbits. Afr J Biotechnol. 2007; 12(6): 1369-1372.doi: 10.5897/AJB2007.000-2192

22. Fink AL. Protein aggregation: folding aggregates, inclusion bodies and amyloid. Fold Des. 1998;3(1):R9-R23. doi:10.1016/ S1359-0278(98)00002-9

23. Singh SM, Panda AK. Solubilization and refolding of bacterial inclusion body proteins. J Biosci Bioeng. 2005;99(4):303-310. doi: 10.1263/jbb.99.303

24. Rhodes DG, Laue TM. Chapter 38 "Determination of Protein Purity" In: Richard RB, Murray PD, editors. Methods in Enzymology, Academic Press; 2009. p. 677-689.doi: 10.1016/ s0076-6879(09)63038-x.

25. Barbieri MR, Carvalho MGd, Zambolim EM, Zerbini FM. Expressão em Escherichia coli da proteína capsidial do Watermelon mosaic virus e produção de anti-soro. Fitopatol Bras. 2004;29(2):215-219. doi: 10.1590/s010041582004000200017

26. Childs LM, Baskerville EB, Cobey S. Trade-offs in antibody repertoires to complex antigens. Phil Trans. $R$ Soc. B. 2015;370(1676):20140245. doi: 10.1098/rstb.2014.0245

27. Crompton PD, Kayala MA, Traore B, Kayentao K, Ongoiba A, Weiss GE, et al. A prospective analysis of the Ab response to Plasmodium falciparum before and after a malaria season by protein microarray. Proc. Natl Acad Sci. USA. 
2010;107(15):6958-6963. doi: 10.1073/pnas.1001323107.

28. Nahum JR, Godfrey-Smith P, Harding BN, Marcus JH, CarlsonStevermer J, Kerr B. A tortoise-hare pattern seen in adapting structured and unstructured populations suggests a rugged fitness landscape in bacteria. Proc. Natl Acad Sci. US A. 2015:201410631. doi: 10.1073/pnas.1410631112.

29. Parameswaran P, Liu Y, Roskin KM, Jackson KK, Dixit VP, Lee J-Y, et al. Convergent antibody signatures in human dengue. Cell host microbe. 2013;13(6):691-700. doi: 10.1016/j. chom.2013.05.008.

30. Roos WH, Bruinsma R, Wuite GJL. Physical virology. Nat.
Phys. 2010;6(10):733-743.doi:10.1038/nphys1797

31. 31. Zlotnick A, Aldrich R, Johnson JM, Ceres P, Young MJ. Mechanism of capsid assembly for an icosahedral plant virus. Virology. 2000;277(2):450-456. doi: 10.1006/viro.2000.0619

32. Rowhani A. Use of F(ab') 2 Antibody Fragment in ELISA for Detection of Grapevine Viruses. Am J Enol. Vitic. 1992;43(1):3840.

33. Pinck L, Fuchs M, Pinck M, Ravelonandro M, Walter B. A satellite RNA in Grapevine fanleaf virus strain F13. J. Gen. Virol. 1988;69:233-239. 